\title{
Treatment of rapidly progressive rheumatoid pneumoconiosis
}

\author{
DEWI DAVIES \\ Ransom Hospital, Mansfield, Nottinghamshire
}

\begin{abstract}
Davies, D. (1973). British Journal of Industrial Medicine, 30, 396-401. Treatment of rapidly progressive rheumatoid pneumoconiosis. Rheumatoid pneumoconiosis is often a fairly benign condition but in some patients it progresses rapidly and causes severe disability. One patient with rheumatoid pneumoconiosis was treated with chloroquine followed by corticosteroids, and another patient was treated with corticosteroids only. Both showed considerable symptomatic and objective improvement with radiographic regression. Treatment has been continued for five and six years respectively but some progression of the disease has again occurred over this time and with a reduced dose of corticosteroids.
\end{abstract}

The development of progressive massive fibrosis (PMF) in coal workers correlates well with the total amount of dust in the lungs, as indicated by the background of simple pneumoconiosis. The prevalence of PMF rises from very low levels in men with category 0 or category 1 pneumoconiosis to about $30 \%$ in those with category 3 (Cochrane, 1962). When PMF appears with a background of category 0 or category 1 there is a likelihood that this will prove to be rheumatoid pneumoconiosis, the subjects having rheumatoid arthritis or rheumatoid factor in their serum(Lindars and Davies, 1967). The presence of rheumatoid disease reduces the amount of dust retention that is usually necessary for the development of PMF. For the purposes of this paper rheumatoid PMF is defined as rheumatoid pneumoconiosis where one or more lesions are $1 \mathrm{~cm}$ in diameter or larger.

Once PMF has appeared, its rate of progression is known to correlate only with age: the younger the man, the faster the progression (Cochrane et al., 1956). It might be expected that a faster rate of progression would be seen in rheumatoid PMF where there is an obvious disturbance of autoimmunity. But in a reasonably long-term study of coal miners with rheumatoid pneumoconiosis (Davies and Lindars, 1968 ) it was found that in some the disease was mild and static and not associated with disability. Some men, however, particularly those with obvious arthritis and a substantial background of simple pneumoconiosis, showed considerable progression and disability.

This paper reports the results of treatment in two coal miners with rapidly progressive rheumatoid PMF in which an attempt was made to slow down or reverse the PMF using drugs known to suppress rheumatoid arthritis.

\section{Case reports}

Case 1

H.T. worked underground from 1935 to 1961 , with the exception of five years in the Army. The first chest radiograph taken in 1961, when he was 37 years old, showed category 2 simple pneumoconiosis, the opacities being predominantly of the punctiform type. His application to a Pneumoconiosis Panel for certification was rejected and he continued underground work. A further radiograph in 1963 showed category 3 simple pneumoconiosis and he was then certified. He remained at the coal face until 1965 when he changed to work on supplies.

In 1966 he became short of breath and the radiograph showed considerable deterioration (Fig. 1). There were multiple irregular opacities throughout both lungs, the largest being $1 \mathrm{~cm}$ in diameter. Six months later he developed rheumatoid arthritis and took an office job.

He was referred to me in December 1967 because of increasing dyspnoea and bilateral pleural pain of several 
FIG. 1. Case 1. Chest radiograph in May 1966 showing multiple widespread irregular nodules measuring up to $1 \mathrm{~cm}$ in diameter.

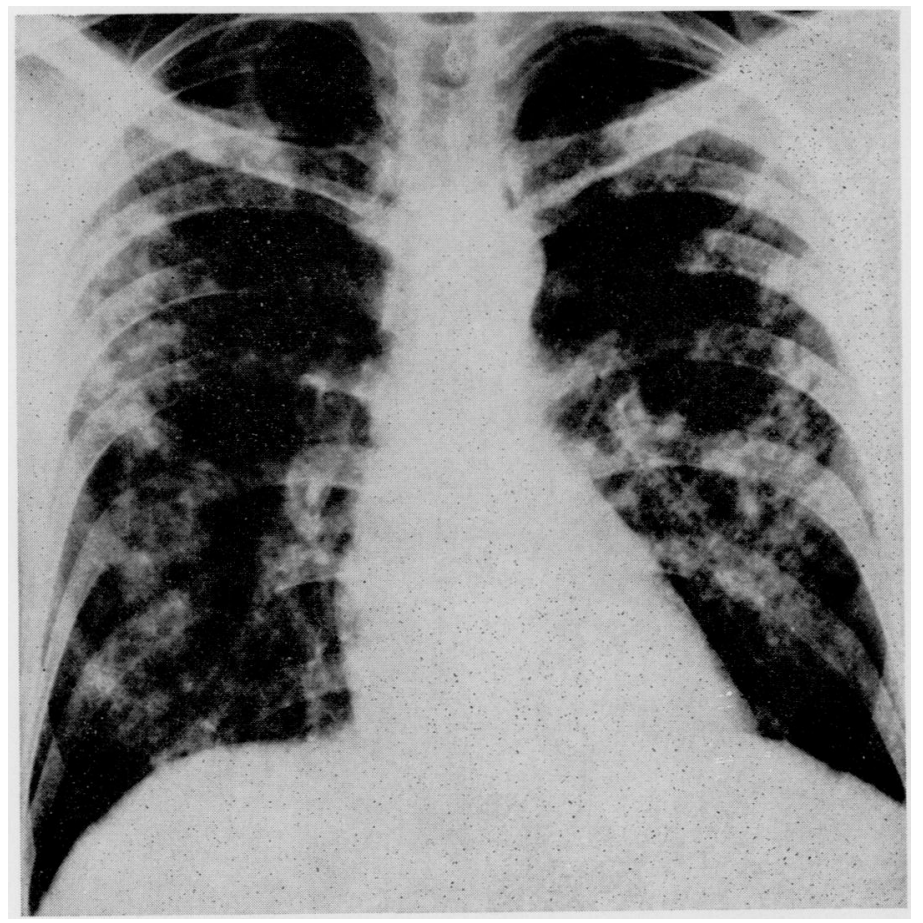

FIG. 2. Case 1. By December 1967 there was marked progression. There is some cavitation in a nodule below the left clavicle. 
months' duration. He smoked a pipe but had very little cough or sputum. On examination he had active polyarthritis but no subcutaneous nodules. He looked unwell and there were pleural rubs over both lungs. Ventilatory tests (vital capacity and forced expiratory volume in 1 second) showed marked restriction while the carbon monoxide diffusing capacity and arterial carbon dioxide were normal. Radiographs showed extensive large irregular opacities in both lungs and cavitation below the left clavicle (Fig. 2).

The pain and pleural rubs persisted and in January 1968 he was started on chloroquine sulphate, $600 \mathrm{mg}$ daily. Within three weeks the pain became much less severe, the pleural rubs disappeared, he became less dyspnoeic, and his arthritis improved. After six weeks he was free of chest pain and went back to work. Chloroquine was reduced to $400 \mathrm{mg}$ daily after two months and was stopped after four months because of the appearance of retinal changes, though vision was not affected. He was then put on prednisolone, $15 \mathrm{mg}$ daily. Moderate radiographic improvement was seen throughout the period of treatment and the appearances in June 1968 are shown (Fig. 3).

He remained fairly well thereafter, and the daily dose of prednisolone was reduced in steps to $7.5 \mathrm{mg}$ in August 1970. In 1971 he had left pleural pain for two weeks but this cleared without a change in treatment.

At the end of 1972 he felt well but was dyspnoeic on
FIG. 3. Case 1 in June 1968 showing moderate reduction in the size of nodules after six months' treatment. hills and stairs. He had a slight cough with sputum and had given up smoking. The joints were occasionally painful but showed no swelling nor deformity. His fundi showed some macular pigmentation. The improvement in vital capacity (VC) was maintained but there had been a fall in the forced expiratory volume in one second $\left(F_{1}\right)$ from the best level reached in June 1968 (Table 1). There hat also been some radiographic deterioration since that time but the appearances were similar to those before treatment (Fig. 2). The dose of prednisolone was increased to $10 \mathrm{mg}$ daily. Tubercle bacilli were not found in the sputum at any time.

\section{Case 2}

W.P. began working underground in 1926 at the age of 14. He did not go on to the coal face until 1937 and he became a shot firer in 1958 . He was referred to me in 1960 complaining of some cough, sputum, and mild dyspnoea for two years. He had given up smoking in 1955. There was no significant abnormality on examination and his chest radiograph showed category 2 simple pneumoconiosis. The nodules were fairly scanty and variable in size, a few measuring up to $8 \mathrm{~mm}$ in diameter. He was certified by the Pneumoconiosis Medical Panel as a case of pneumoconiosis.

He continued with underground work but was off periodically with episodes of cough and sputum. His ventilatory tests (vital capacity and forced expiratory 
TABLE 1

Case 1. Results of Ventilatory Tests, Rose-Waaler Test, and Erythrocyte Sedimentation Rate: STARTED ON CHLOROQUINE JANUARY 1968

\begin{tabular}{|c|c|c|c|c|c|c|}
\hline & & $\begin{array}{l}V C \\
(l .)\end{array}$ & $\begin{array}{c}F E V_{1} \\
(l .)\end{array}$ & $\begin{array}{c}\text { Rose-Waaler } \\
\text { titre }\end{array}$ & $\begin{array}{l}\text { ESR (Westergren) } \\
(\mathrm{mm} \text { in } 1 \mathrm{hr})\end{array}$ & $\begin{array}{l}\text { Prednisolone } \\
\text { (mg daily) }\end{array}$ \\
\hline 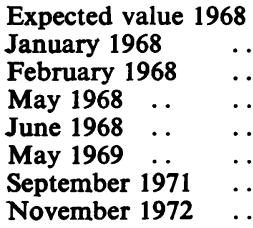 & $\begin{array}{l}\cdots \\
\cdots \\
\cdots \\
\cdots \\
\cdots \\
\cdots \\
\ldots\end{array}$ & $\begin{array}{l}3 \cdot 50 \\
1 \cdot 90 \\
2 \cdot 60 \\
2 \cdot 60 \\
3 \cdot 00 \\
2 \cdot 80 \\
2 \cdot 75 \\
2 \cdot 70\end{array}$ & $\begin{array}{l}2 \cdot 90 \\
1 \cdot 70 \\
2 \cdot 50 \\
2 \cdot 55 \\
2 \cdot 85 \\
2 \cdot 20 \\
2 \cdot 15 \\
2 \cdot 00\end{array}$ & $\begin{array}{c}1: 320 \\
1: 160 \\
1: 160 \\
\\
1: 80 \\
\text { Negative } \\
1: 64\end{array}$ & $\begin{array}{l}96 \\
84 \\
59 \\
\\
45 \\
44 \\
34\end{array}$ & $\begin{array}{l}15 \\
12 \cdot 5 \\
10 \\
7 \cdot 5 \\
10\end{array}$ \\
\hline
\end{tabular}

volume in 1 second) showed evidence of moderate airways obstruction. Rheumatoid arthritis developed in 1963 and he left underground work. By 1964 there was marked radiographic deterioration. A large opacity on the right measured $8 \times 3.5 \mathrm{~cm}$ and there were multiple nodules up to $1.2 \mathrm{~cm}$ in diameter in the remainder of the lungs. A year later he had melanoptysis and haemopty. sis and several cavities appeared in the area of PMF in the right lung. The cavities filled up again and the other opacities on both sides became larger by early 1967 (Fig. 4). At that time he was more short of breath, still coughing up some blood occasionally, and he had some right-sided pleuritic pain.

In January 1967 he was given prednisolone, $15 \mathrm{mg}$ daily. Over a few weeks the pleuritic pain disappeared, his breathlessness became less, and the ventilatory and diffusing capacity tests improved (Table 2). The arthritis remained troublesome. There was considerable radio-
FIG. 4. Case 2. Radiograph in January 1967 showing multiple irregular opacities in both lungs, more extensive on the right.

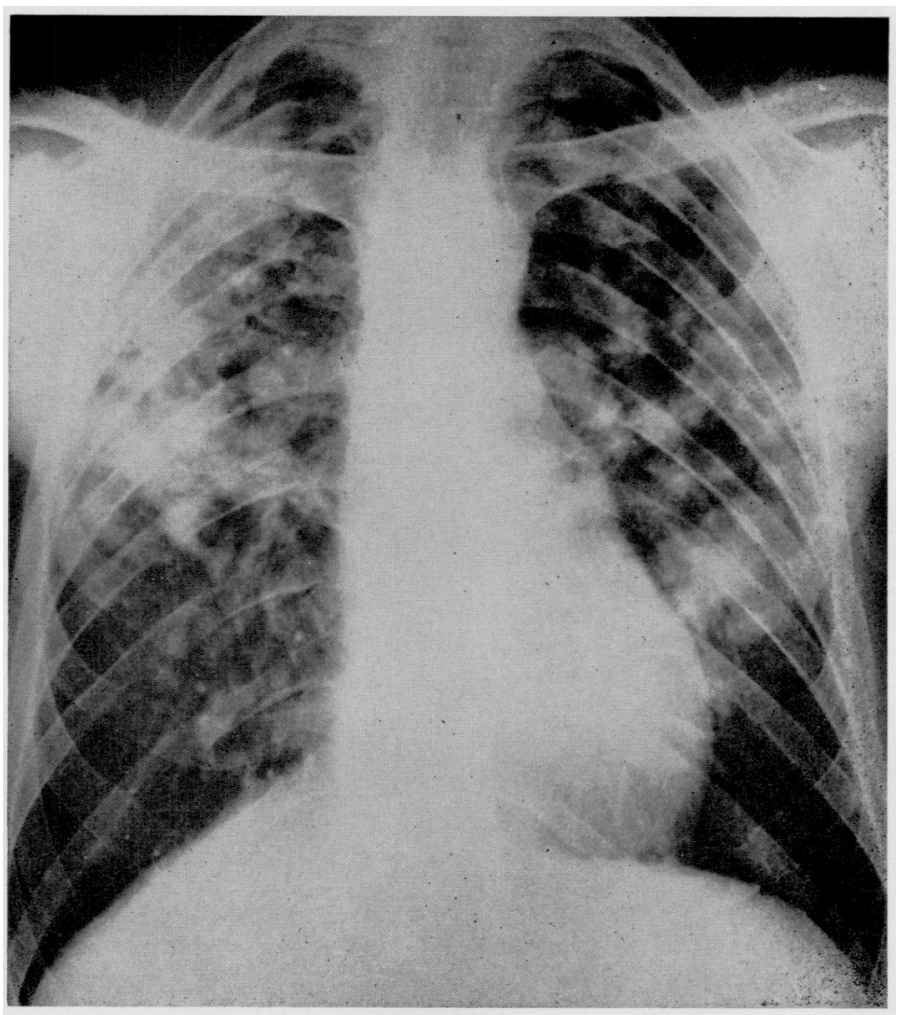


TABLE 2

Case 2. Results of Ventilatory Tests, Carbon Monoxide Diffusing Capacity (DCO, Steady State), Rose-WaAler Test and ERythrocyte Sedimentation Rate

\begin{tabular}{|c|c|c|c|c|c|c|}
\hline & $\begin{array}{l}V C \\
(l .)\end{array}$ & $\begin{array}{c}F E V_{1} \\
(l .)\end{array}$ & $\begin{array}{c}D C O \\
(\mathrm{ml} / \mathrm{mm} \mathrm{Hg} / \mathrm{min})\end{array}$ & $\begin{array}{c}\text { Rose-Waaler } \\
\text { titre }\end{array}$ & $\begin{array}{c}\text { ESR } \\
\text { (Westergren) } \\
\text { (mm in } 1 \text { hour })\end{array}$ & $\begin{array}{l}\text { Prednisolone } \\
\text { (mg daily) }\end{array}$ \\
\hline $\begin{array}{l}\text { Expected value } 1962 . \\
\text { May } 1962 \\
\text { July } 1964 \quad \ldots \\
\text { December } 1966 \\
\text { January } 1967 \ldots \\
\text { March } 1967 \quad \ldots \\
\text { September } 1967 \\
\text { July } 1968 \quad \ldots \\
\text { June } 1970 \\
\text { December } 1971 \\
\text { October } 1972 \ldots\end{array}$ & $\begin{array}{l}3 \cdot 80 \\
4 \cdot 80 \\
3 \cdot 30 \\
3 \cdot 10 \\
\\
3 \cdot 20 \\
3 \cdot 50 \\
3 \cdot 60 \\
3 \cdot 60 \\
3 \cdot 10 \\
2 \cdot 90\end{array}$ & $\begin{array}{l}3 \cdot 30 \\
2 \cdot 80 \\
2 \cdot 90 \\
2 \cdot 25 \\
2 \cdot 70 \\
2 \cdot 70 \\
2 \cdot 85 \\
2 \cdot 60 \\
2 \cdot 40 \\
2 \cdot 40\end{array}$ & $\begin{array}{r}17 \cdot 9 \\
\\
9 \cdot 9 \\
\\
17 \cdot 3 \\
16 \cdot 1 \\
16 \cdot 8 \\
\\
9 \cdot 4 \\
11 \cdot 4\end{array}$ & $\begin{array}{c}\text { Positive } \\
1: 160 \\
\\
1: 320 \\
1: 160 \\
1: 320 \\
1: 64 \\
1: 32\end{array}$ & $\begin{array}{r}22 \\
30 \\
\\
\\
3 \\
22 \\
90 \\
16 \\
10\end{array}$ & $\begin{array}{l}15 \\
12.5 \\
10 \\
7 \cdot 5 \\
10 \\
6.25 \\
6.25\end{array}$ \\
\hline
\end{tabular}

graphic improvement by June 1968 (Fig. 5) and prednisolone was reduced to $7.5 \mathrm{mg}$ daily. A year later the dose was increased to $10 \mathrm{mg}$ because of radiographic deterioration and a rise in erythrocyte sedimentation rate. He gave up work because of arthritis, some shortness of breath, and domestic difficulties.
$\mathrm{He}$ is now on $6.25 \mathrm{mg}$ of prednisolone a day. He is still unable to keep up with people of his age on the flat, and the lung function test results have fallen to the $\mathbf{1 9 6 6}$ levels. Gradual radiographic deterioration has occurred but the position is still better than when he started prednisolone (Fig. 4). Sputum tests for tubercle bacilli

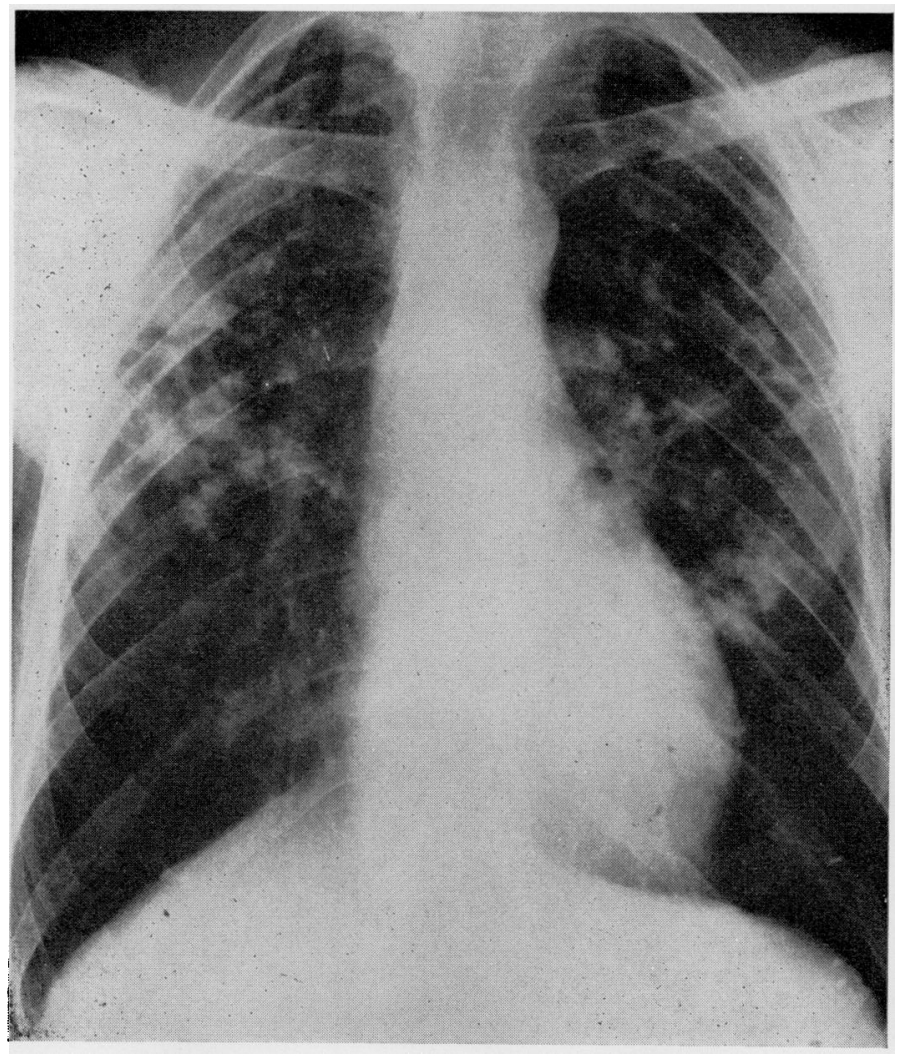

FIG. 5. Case 2. In June 1968, after 18 months on prednisolone, the opacities are much smaller. 
have been repeatedly negative. The arterial carbon dioxide tension was normal before the start of treatment and remains so. The oxygen tension is also normal but was not measured at the start.

\section{Discussion}

Kandus (1971) treated 22 patients with rheumatoid pneumoconiosis with chloroquine sulphate, $250 \mathrm{mg}$ daily, for a minimum of six months. No effect on the evolution of the disease was observed. The duration of treatment seems to have been too short and it is doubtful if the dose was adequate. Personal experience has shown that sarcoid lesions suppressed by chloroquine in a larger dose may progress when the chloroquine is reduced to this level. Some beneficial effect from corticosteroids has been claimed by Ramirez, Lopez-Majano, and Schultze (1964).

The best way of judging whether treatment produces regression or slows the progression of rheumatoid pneumoconiosis would be to allocate a number of patients at random to treatment and control groups. Because some patients have nonprogressive or slowly progressive disease it seems likely that a fairly large number would be required and treatment should be continued for some years before conclusions could be reached. Many patients have obviously been treated with corticosteroids and other drugs solely because of their arthritis. An analysis of the rate of progress of the pneumoconiosis in such patients, compared with others not so treated, would be feasible though very difficult. As studies of this kind have not been reported it seems reasonable to draw some conclusions from observations on two rapidly deteriorating cases.

The rheumatoid pneumoconiotic nodules in case 1 were evidently subpleural, as is often the case with rheumatoid nodules in the lungs of people not exposed to dust (Davies, 1966). Chloroquine was chosen as initial treatment simply to see if it worked. The response before changing to corticosteroids was gratifying and further improvement was seen on prednisolone. Though there has been some deterioration since, the radiographic picture now is no worse than five years ago and he has no pleural complications. The striking early improvement in ventilatory tests was more the result of pain relief than of changes within the lung.
In case 2 , the early radiographic improvement was more striking. Again, with the passage of time the disease is showing slow progression but the position is still better than six years ago.

The evidence is strong that treatment produced a marked reversal of previously rapid deterioration. The dose of prednisolone was kept low and a larger one might have prevented the gradual deterioration that is now occurring. In judging the results of treatment in rheumatoid pneumoconiosis it has to be remembered that the nodules often cavitate and shrink. They usually fill up again but this is not invariable and some are replaced by linear scars. Though cavitation was evident at various stages in these patients, it does not account for their improvement.

The majority of patients with rheumatoid pneumoconiosis do not merit treatment, but in a few with rapidly progressive disease the prognosis is bad and there is now some evidence that treatment can help. These two men were selected for treatment from about 100 patients with rheumatoid pneumoconiosis known to me.

\section{References}

Cochrane, A. L. (1962). The attack rate of progressive massive fibrosis. British Journal of Industrial Medicine, 19, 52-64. , Carpenter, R. G., Clarke, W. G., Jonathan, G., and Moore, F. (1956). Factors influencing the radiological progression rate of progressive massive fibrosis. British Journal of Industrial Medicine, 13, 177-183.

Davies, D. (1966). Pyopneumothorax in rheumatoid lung disease. Thorax, 21, 230-235.

- , and Lindars, D. C. (1968). Rheumatoid pneumoconiosis, a clinical study. American Review of Respiratory Diseases, 97, 617-629.

Kandus, J. (1971). Results of long-term chloroquine therapy in rheumatoid pneumoconiosis. Studia Pneumologica et Phtiseologica, Cechoslovaca, 31, 229-232. (In Czech, English abstract).

Lindars, D. C., and Davies, D. (1967). Rheumatoid pneumoconiosis; a study in colliery populations in the East Midlands coal field. Thorax, 22, 525-532.

Ramirez, J., Lopez-Majano, V., and Schultze, G. (1964). Caplan's syndrome. A clinicopathologic study. American Journal of Medicine, 37, 643-652.

Received for publication December 1, 1972

Accepted for publication March 3, 1973 